\title{
A TRNSYS dynamic simulation model for a parabolic trough solar thermal power plant
}

\author{
Ahmed Remlaoui ${ }^{1, *}$, Mohammed Benyoucef ${ }^{2}$, Djamel Assi $^{2}$, Driss Nehari ${ }^{1}$ \\ ${ }^{1}$ Smart Structure Laboratory, University Center of Ain-Témouchent, ALGERIA \\ ${ }^{2}$ Department of Mechanical Engineering, University Center of Ain-Témouchent, 46000 Ain-Témouchent, ALGERIA \\ donremlaoui@gmail.com
}

\begin{abstract}
This paper presents a validated TRNSYS model for a thermodynamic plant with parabolic trough solar thermal power (PT). The system consist of trough solar collector (PTC) as well as auxiliary components.. The simulation of the system has been done during the day (01/01) under the meteorological conditions of Ain Témouchent city (Algeria). The model compared the energy performance of the systems: case (1) - Rankine cycle facility with solar field and case (2)Rankine cycle facility without solar field. The results showed that the present model has a good agreement with the experimental data of the literature. In case (1), PTC fluid outlet temperature reach the maximum value $330^{\circ} \mathrm{C}$, Work of the steam turbine increase from the $9 \mathrm{hr}$ to reach its maximum value $856 \mathrm{KJ} / \mathrm{Kg}$ at $13 \mathrm{hr}$. In case (2), the maximum value of the power remains constant from the beginning of the simulation to 1hr00. Since the flow of fuel (gas natural) consumed does not change throughout the operating period.
\end{abstract}

Keywords: TRNSYS, Solar thermal power plant, Rankine cycle, parabolic trough power.

Received: 29/09/2019 - Accepted: 10/11/2019

\section{Introduction}

Electricity generation using a hybrid system combining several renewable energy sources is of great interest to developing countries, such as the Maghreb countries. It is well known that generate energy from a solar thermal system with the following technologies are currently used:

1. Parabolic trough (PTC) collector;

2. Fresnel linear reflector (LFR);

3. Sterling dish and Solar energy tower [1].

Among these technologies, the parabolic collector is more popular and is used in many places around the world. As a result, large concentrated solar power (CSP) facilities are PTC technology. Several works was realized on TRNSYS (Transient Systems Simulation) of solar thermal power station. Jones et al. [2] created a 30 MWe SEGS VI parabolic collector base plant model in TRNSYS to evaluate solar field and power cycle behavior. Kolb [3] evaluates the performance of the 1 MWe Sugurao solar power plants with and without thermal storage using the TRNSYS software. The objective of this work is to present the simulation of the hybrid solar field and power cycle model. The STEC library of the TRNSYS software is used for an Algerian site (Ain Témouchent) and meteorological data is provided by the Meteonorm software [4]. Our goal in this study is the design of a Rankine cycle facility with and without solar field by TRNSYS software.

\section{Presentation of the parabolic trough solar thermal power plant used}

In the first part, we used the Rankine cycle with the solar field (Figure 1). The components of the steam cycle are steam generators (economizer, evaporator, and overheater), three stage steam turbine, condenser, pump, degasser, subcooler, preheater and solar field (parabolic trough). The objective of the collector field is to produce electricity from the thermal installation. The system consists of a parabolic trough collector type field connected to the Rankine cycle through a series of heat exchangers. The heat transfer fluid (THERMINOL VP-1) is heated by circulating in the absorbers of the parabolic concentrators (solar field) and returns to the Rankine type power cycle, the role of the coolant is to transport the heat from the hot source ( solar rays concentrate in the parabolic trough). The average temperature of the heat transfer fluid changes according to the weather variations from one hour to another during one year (8760 hours). This fluid is pumped with a constant flow to the steam generator, which consists of an economizer, evaporator and superheater.

The heat exchangers are of the counter flow type. Heat transfer fluid (HTF) with Rankine cycle water flow is in opposite directions. The heat transfer fluid enters the superheater at high temperature before passing to the steam generator where the water of the power cycle undergoes a phase change from the liquid state to the vapor state. Then, the heat transfer fluid passes through 
the economizer where yields to the water which is in the liquid state (called feeding) its energy. Finally, the fluid is recirculated through the solar field. Water before returning to the economizer to complete the cycle the supply water in the liquid state exiting the condenser passes through degasser and then has preheater.

This plant also contains a 3-stage turbine namely high pressure, medium pressure and low pressure and two steam withdrawals that communicate with the preheaters. This withdrawn steam is used to heat the feed water before it enters the economizer to increase cycle efficiency. The outgoing steam at the low-pressure turbine is condensed in a condenser.

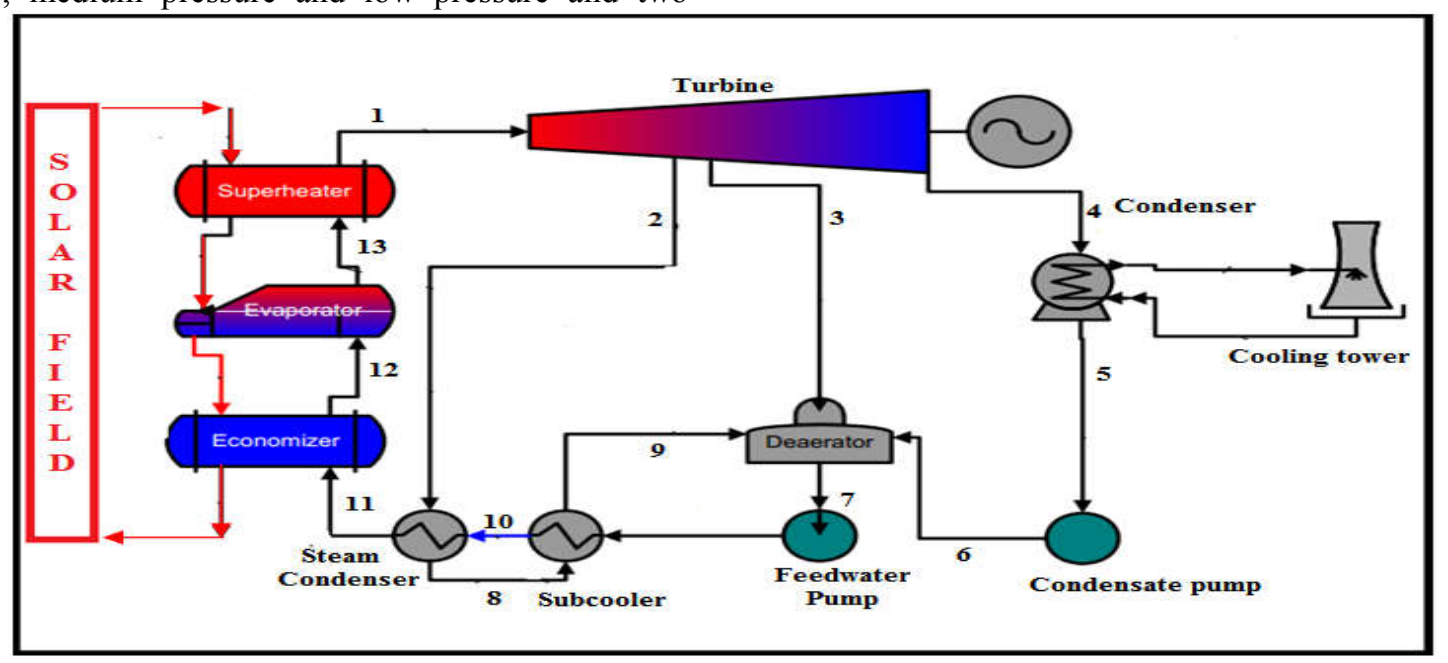

Figure 1. Schematic diagram of the Rankine cycle with solar field

\section{System simulation using TRNSYS}

TRNSYS (Transient Systems Simulation) is a complete and extensible simulation environment for the transient simulation of systems, including multi-zone buildings. It is used by engineers and researchers around the world to validate new energy concepts, from simple domestic hot water systems to the design and simulation of buildings and their equipment, including control strategies, occupant behavior, alternative energy systems (wind, solar, photovoltaic, hydrogen systems) [5].

The Solar Thermal Electric Component (STEC) libraries were developed by Peter Schwarzbozl (DLR, Germany) and Scott Jones (SNL, New Mexico) in 2002. They are used to simulate thermal systems (solar and conventional) in order to produce electricity. These libraries are not issued as standard with the TRNSYS software [6].

Figure 2 shows the model under Rankine Cycle TRNSYS with solar field and Figure 3 shows the power cycle installation without solar field. Once all the components of the system have been identified, the main components of this model are described and shown in Table 1.

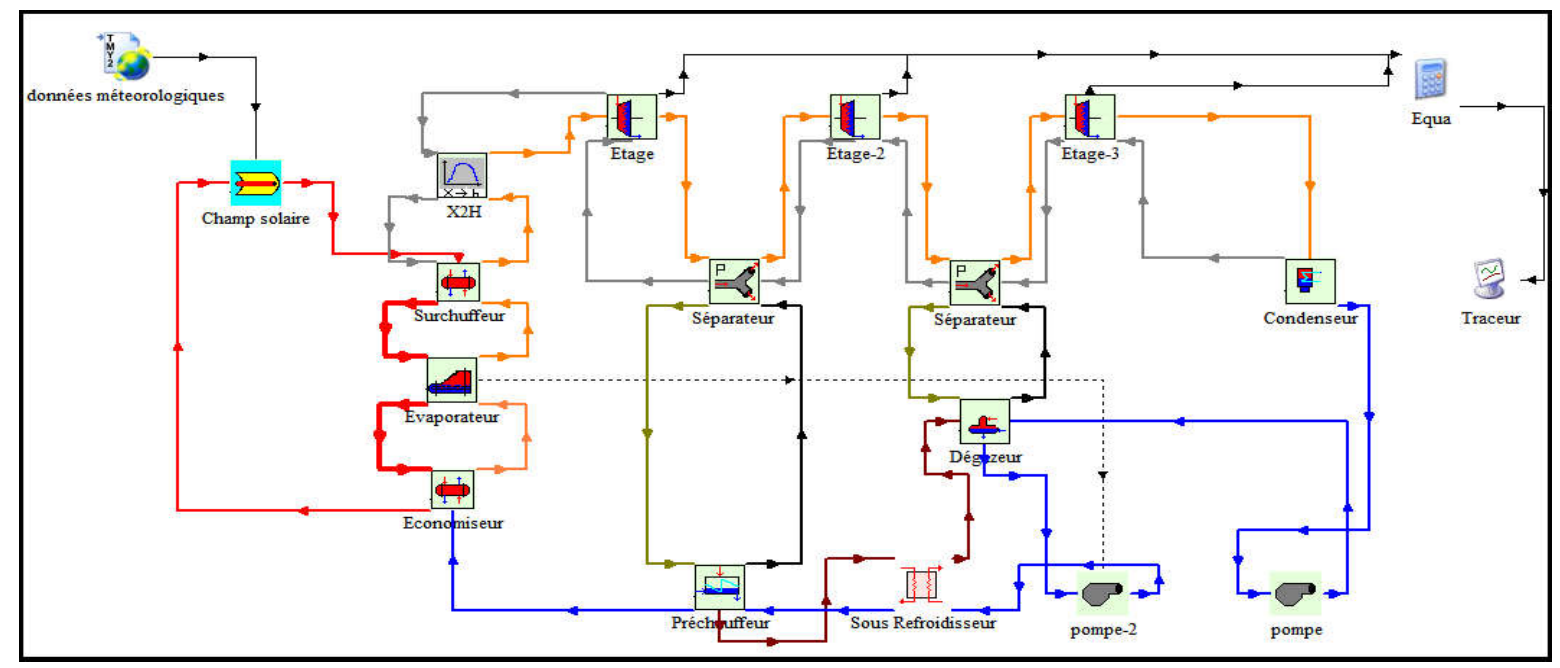

Figure 2. Presentation of the model under TRNSYS of Rankine Cycle with solar field 


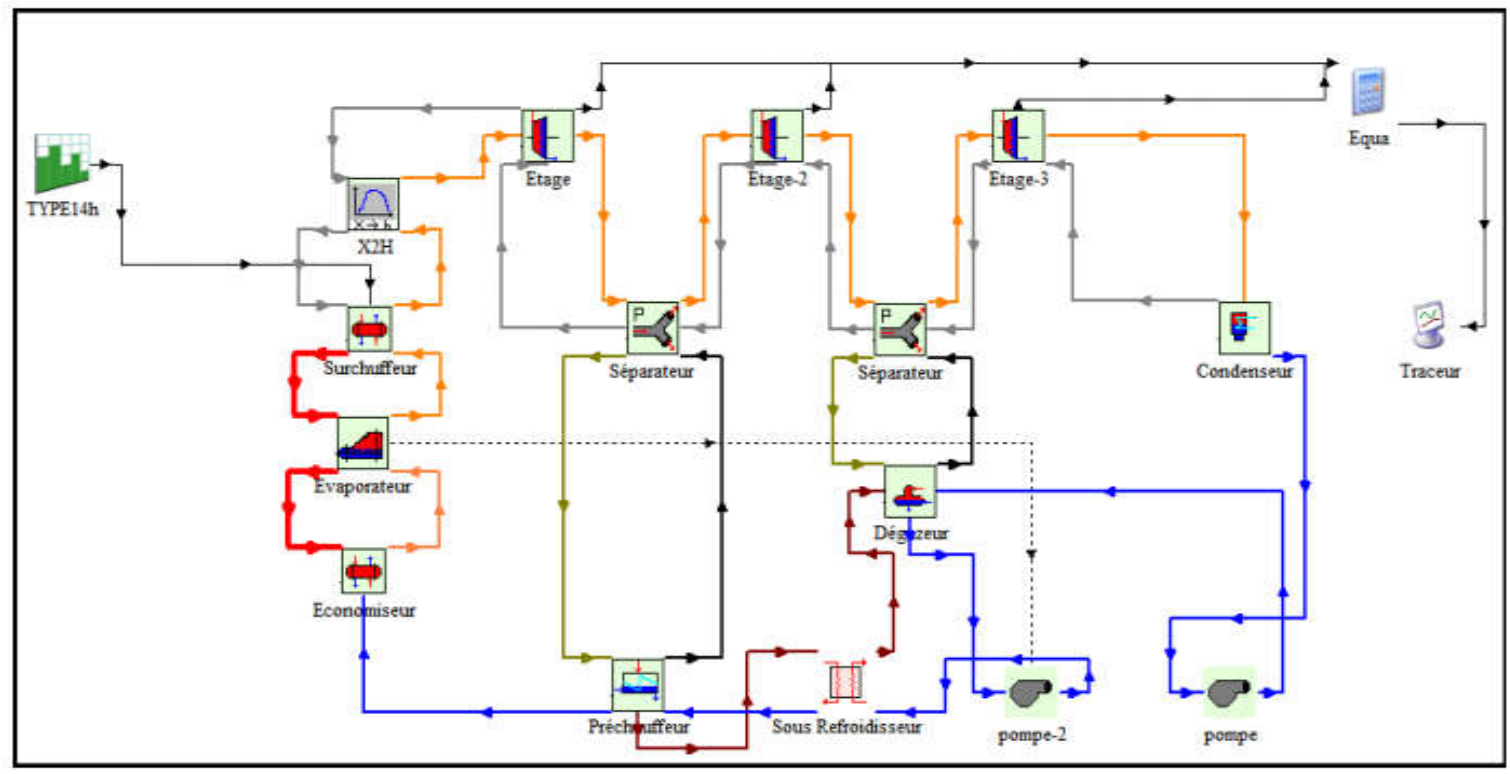

Figure 3. Presentation of the model under TRNSYS of Rankine Cycle without solar field

Table 1. The components and input design parameters in TRNSYS simulation programs

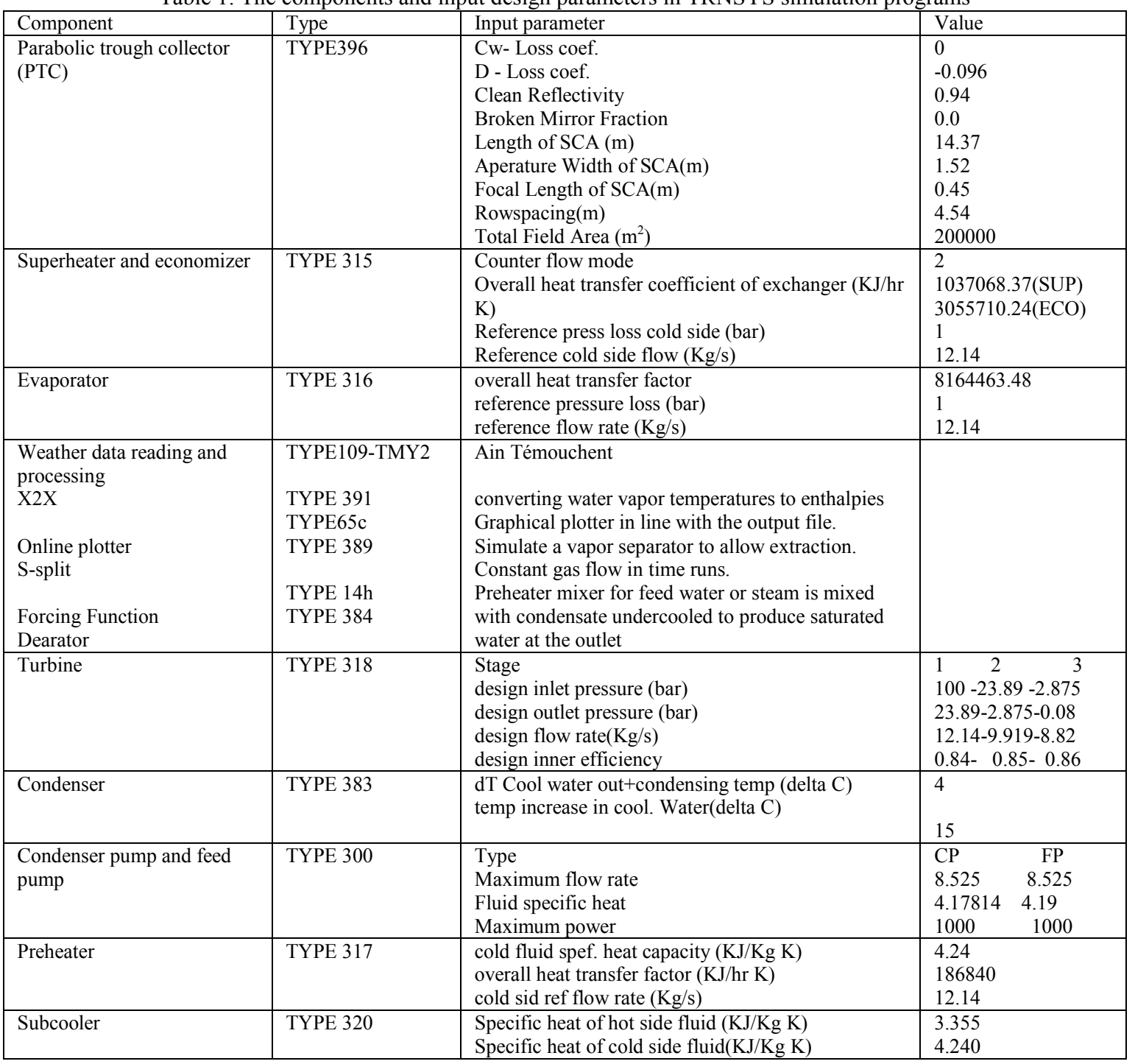




\section{Results and discussion}

\section{IV.1. Meteorological data}

In order to run a simulation for one year and to predict the performance of the SSH system, a typical Meteorological Year of Ain Témouchent (TMY) is used at GMT1 time zone, latitude $35.3060 \mathrm{~N}$ and longitude $1.1470 \mathrm{E}$ were used. Figure 4a shows the solar radiation, (b) wind speed and dry bulb temperature. The peak Total horizontal radiation is approximately 360

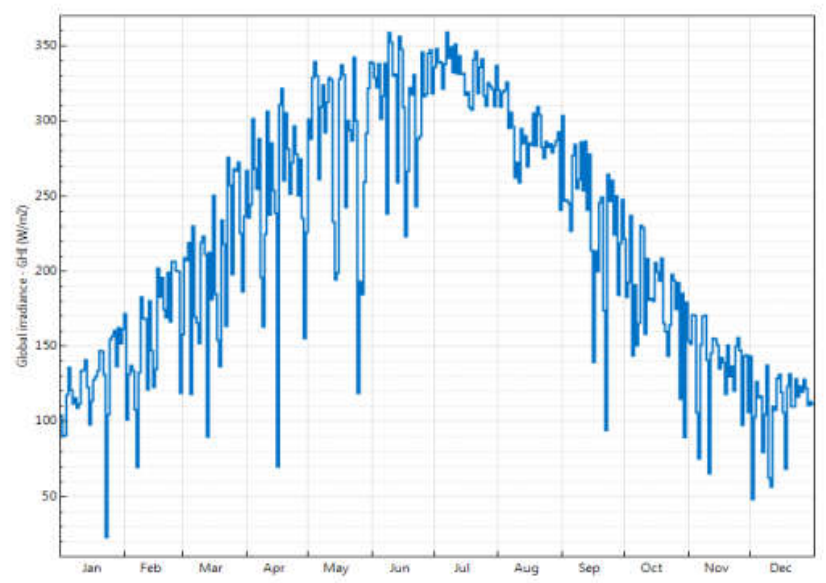

Figure 4a. solar radiation
W. $\mathrm{m}^{-2}$ and occurs in the period from June to Jul. This period is characterized by high ambient temperature with the peak $37^{\circ} \mathrm{C}$ and maximum wind speed is $15 \mathrm{~m} / \mathrm{s}$.

Figure 5 shows the variation of the ambient temperature and annual average humidity. For the variation of the average annual moisture content, we observe that it is less important during the summer season it is balance between 0.48 and 0.63 , so is important during the winter season it is balance between 0.63 and 0.82 .
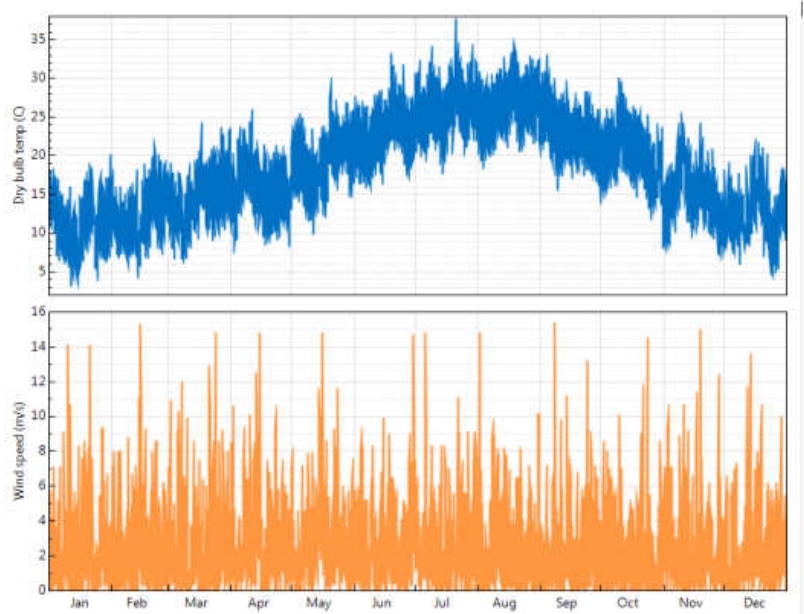

Figure $4 \mathrm{~b}$. Variations of ambient temperature and wind speed over one year

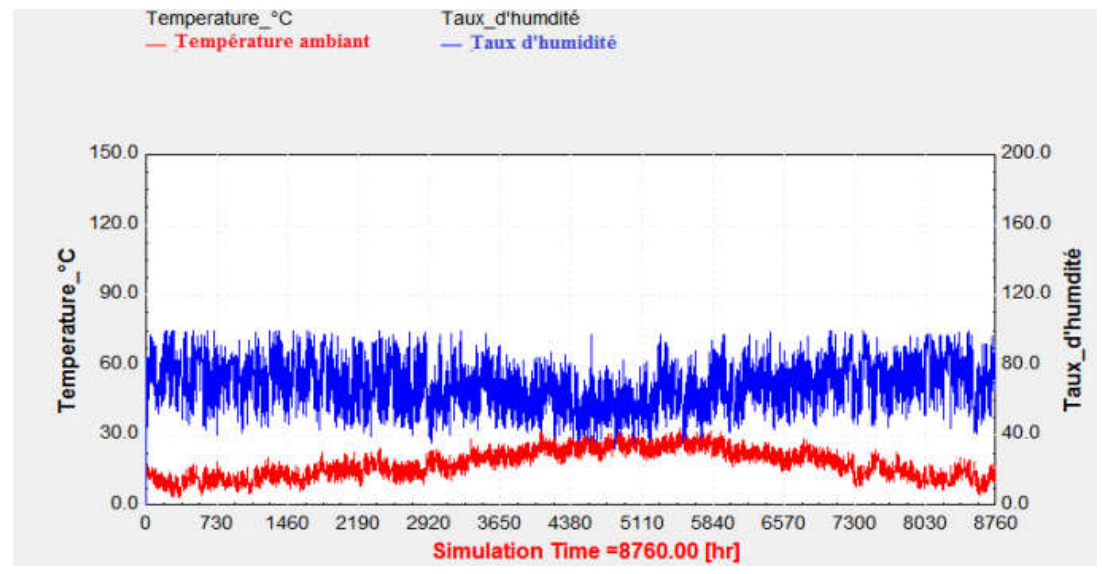

Figure 5. Variations in temperature and annual average humidity

\section{IV.2. Thermal performance evaluation with solar field}

\section{IV.2.1. PTC fluid inlet and outlet temperature}

The curve illustrated in Figure 6 shows that at the beginning of the heating, at $\mathrm{t}=0$ the outlet temperature of the coolant is equal to the temperature of the injected fluid, after the sun rises this temperature increases with solar radiation concentrated to the concentrator opening, it reaches $200{ }^{\circ} \mathrm{C}$ between $09 \mathrm{hr}$ and $10 \mathrm{hr}$ while the inlet temperature reaches $177{ }^{\circ} \mathrm{C}$. It continues its increase to reach the maximum value $330{ }^{\circ} \mathrm{C}$ to $13 \mathrm{hr}$. During the afternoon, it will decrease until it reaches zero. 


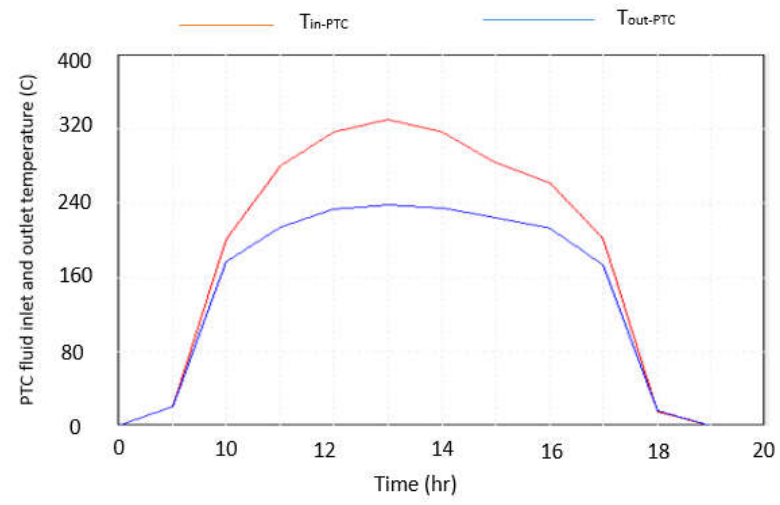

Figure 6. Variation of PTC fluid inlet and outlet temperature during the Day of January 1

\section{IV.2.2. Steam generator temperatures of the fluid on the hot and cold sides}

The curve shown in Figure 7 shows that steam generator fluid temperatures on the hot and cold sides increase to a maximum around $13 \mathrm{hr}$ at the steam generator inlet. This period corresponds to maximum sunlight. With regard to the (cold side), it is noted that the outlet temperature (cold side) in each exchanger will increase and reach the maximum output value $327^{\circ} \mathrm{C}$ to 13:00h. After 13:00h, the exit temperatures on each side and each exchanger will go down when the irradiation of the sun decreases until 18:00h or it will be zero.

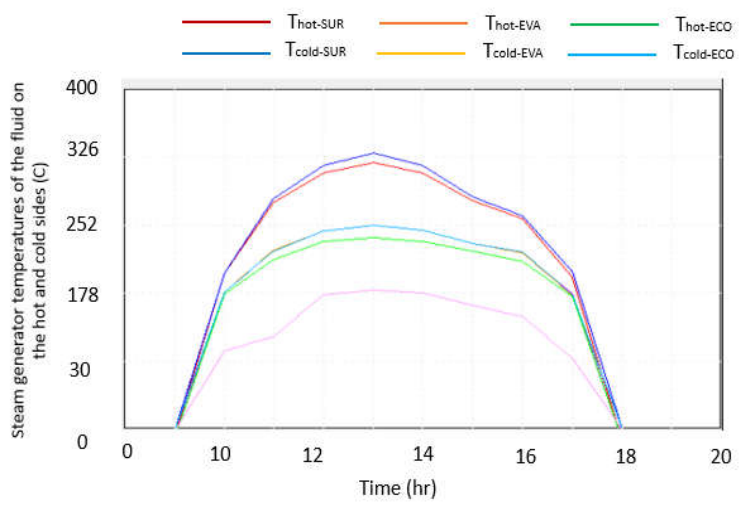

Figure 7. Variation of steam generator temperatures of the fluid on the hot and cold sides during the Day of January 1

\section{IV.2.3. Transferred power}

The curve illustrated in Figure 8 shows the evolution of the transferred power of each exchanger: economizer, evaporator, super heater and condenser. Both types of transferred power $\left(\mathrm{Q}_{\text {in }}\right.$ and $\left.\mathrm{O}_{\text {out }}\right)$ go into an increase from $8 \mathrm{am}$ in the morning to reach a maximum value at $13: 00 \mathrm{~h}$ such that $\mathrm{Q}_{\text {inmax }}=3.9 * 107 \mathrm{KJ} / \mathrm{hr}$ and $\mathrm{Q}_{\text {out,max }}=3.4 * 107$ $\mathrm{KJ} / \mathrm{hr}$, then decrease in the next period to reach the zero value at $18: 00 \mathrm{~h}$.

It is observed that the transferred power used by the system (Qin) is greater than the heat lost $\left(Q_{\text {out }}\right)$, this difference is the main advantage for the increase of the efficiency of the installation.

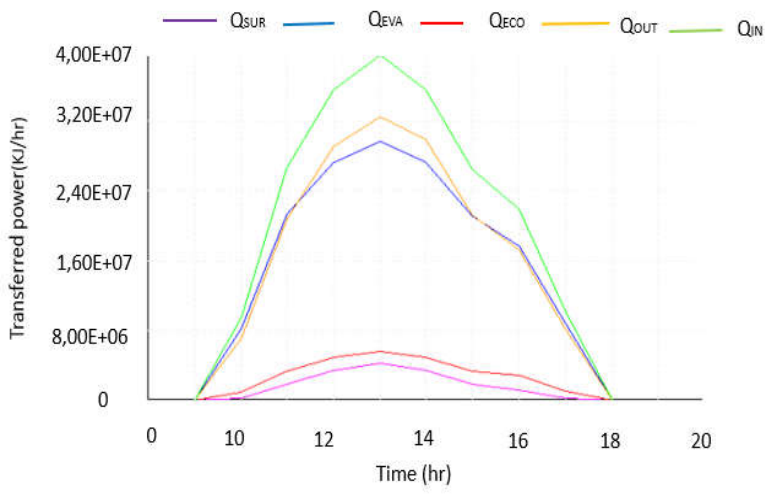

Figure 8. Variation of transferred power during the Day of January 1

\section{IV.2.4. Work of the steam turbine}

Figure 9 shows the evolution of the three stages of the steam turbine and the total work: It is observed that the work begins to increase from the $9: 00 \mathrm{~h}$ to reach its maximum value $856 \mathrm{kj} / \mathrm{kg}$ at 13:00h. Then it starts to decrease after this maximum value so that it is zero at 18:00h. Note also that the intermediate floor work is larger than the floors of the ends.

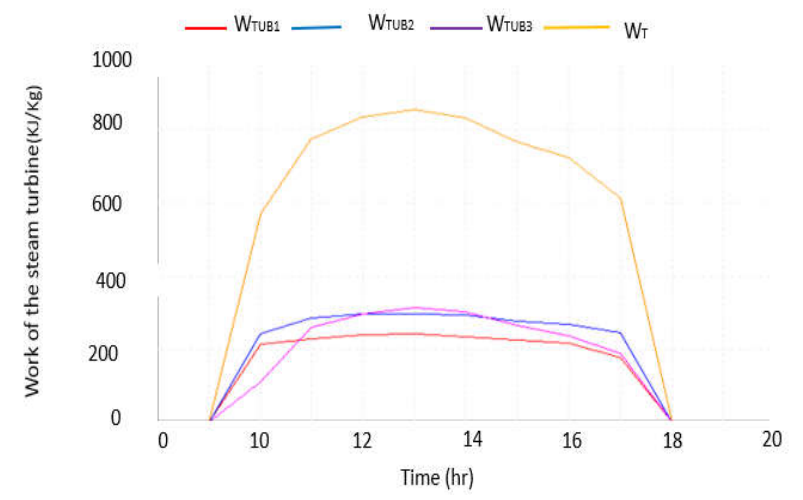

Figure 9. Variation of Work of the steam turbine during the Day of January 1

\section{IV.3. Thermal performance evaluation without solar field}

\section{IV.3.1. Power of the steam turbine}

In this cycle, the thermal performance is almost constant throughout the week, due to the stability of the turbine power used, if for this reason we will take just one day in this cycle to evaluate the thermal behavior of the installation as we have a week of evaluation. In the second part, we will study a plant of the power cycle by the use of natural gas, and the results of this simulation will be presented by the figures below. The curve shown in Figure 10 shows the evolution of the power of each stage obtained by the steam turbine; we note that the maximum value of the power remains constant from the beginning of the simulation to $01: 00 \mathrm{~h}$. Since the flow of fuel (gas natural) consumed does not change throughout the operating period. 


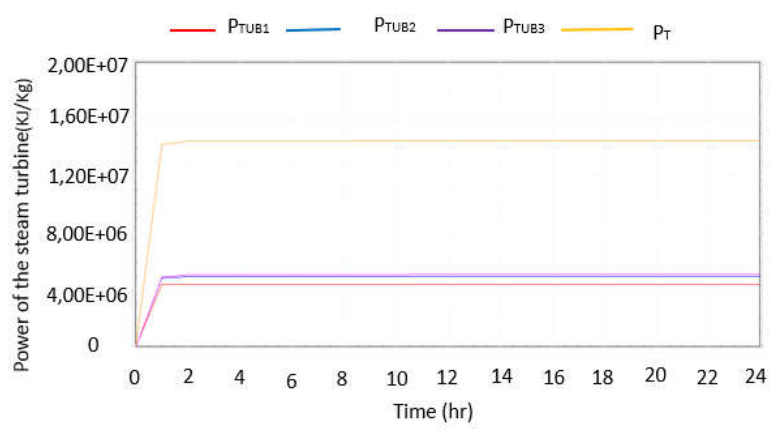

Figure 10. Variation of power of the steam turbine during the Day of January 1

\section{IV.3.2. Transferred power and Work of the steam turbine}

The two curves of figure 11 and 12 remain invariable for the work and the transferred power in both cases have the same max.

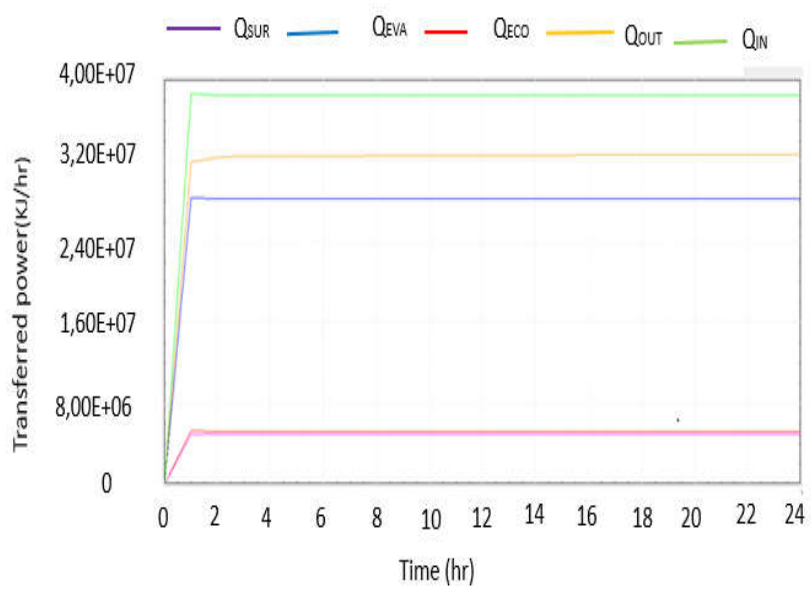

Figure 11. Variation of transferred power during the Day of January 1

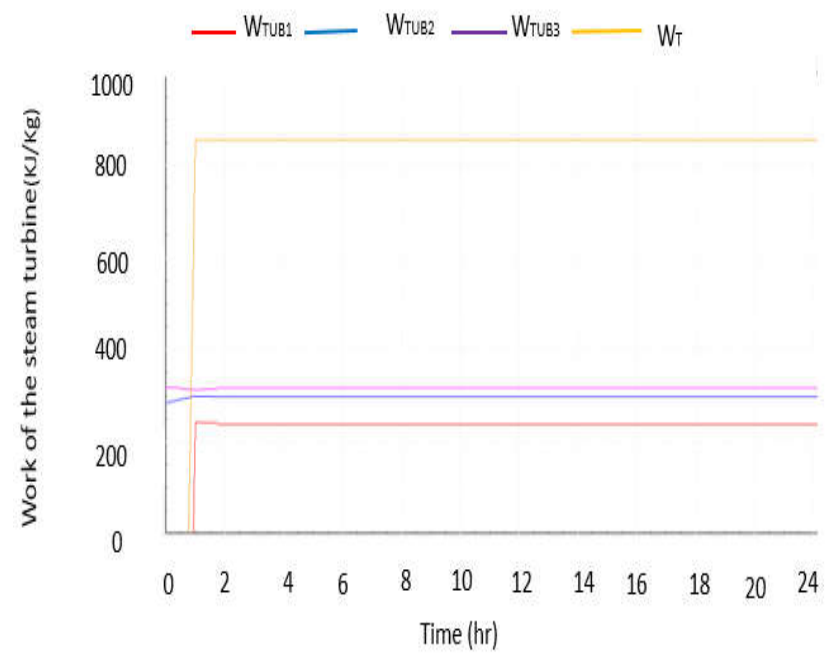

Figure 12. Variation of Work of the steam turbine during the Day of January 1

\section{Conclusion}

This article aims at the study of an installation of the Rankine cycle powered energetically by the solar field; through a modeling, which was carried out by TRNSYS software, knowing that the weather conditions of Ain Témouchent was used for the purpose of, evaluate the thermal behavior of the installation during one week.

Two cases were studied: case (1) - Rankine cycle facility with solar field and case (2) - Rankine cycle facility without solar field. Results obtained showed:

In case (1), PTC fluid outlet temperature reach the maximum value $330^{\circ} \mathrm{C}$, Work of the steam turbine increase from the $9 \mathrm{hr}$ to reach its maximum value 856 $\mathrm{KJ} / \mathrm{Kg}$ at $13: 00 \mathrm{~h}$.

In case (2), the maximum value of the power remains constant from the beginning of the simulation to $1 \mathrm{hr} 00$. Since the flow of fuel (gas natural) consumed does not change throughout the operating period. The results showed that the minimum efficiency of the facility is $13 \%$ in the winter period. For a power equal to $4 \mathrm{MW}$, the natural gas consumption can be gained of $312.4 \mathrm{~kg} / \mathrm{hr}$ in the sunny period.

\section{Acknowledgements}

The authors gratefully acknowledge support from Smart Structure Laboratory of University Center Belhadj Bouchaïb, Ain Témouchent (Algeria).

\section{References}

[1] S. Sukhatme, J. Nayak, "Solar Energy, Principles of Thermal Collection and Storage", 3rd ed., Tata McGraw Hill, Ed. New York, 2009

[2] S. Jones, R. Pitz-Paal, P. Schwarzboezl, V.Blair, R. Cable. "TRNSYS Modelling of the SEGS VI Parabolic Troug Solar Electric Generating System, in Proc". ASME International Solar Energy Conference Solar Forum, Washington DC, paper 01.3, 2004, pp. 109.

[3] G. Kolb, V. Hassani. "Performance Analysis of Thermocline Energy Storage Proposed for the 1 MW Saguaro Solar Trough Plant, in Proc". ASME International Solar Energy Conference, Denver. 15, 2006, pp. 8-13.

[4] P Schwarzboezl. "A TRNSYS Model Library for Solar Thermal Electric Components (STEC)". Reference Manual. Release 3.0, November 2006.

[5] Solar Energy Laboratory, 2000, "TRNSYS, A Transient Simulation Program," University of Wisconsin, Madison, $\mathrm{http}: / /$ sel.me.wisc.edu/trnsys/.

[6] R.Pitz-Paal, S.A Jones. "A TRNSYS Model Library for Solar Thermal Electric Components (STEC)," A Reference Manual, Release 1.0, IEA-Solar Power and Chemical Energy Systems, Task III: Solar Technologies and Applications. 1998 